\title{
Compensação dos dias de greve
}

\author{
Conselho Nacional de Justiça (CNJ)
}

\section{Autos: PROCEDIMENTO DE CONTROLE ADMINISTRATIVO — 0006714- 44.2016.2.00.0000}

Requerente: JEAN PAULO RUZZARIN e outros

Requerido: TRIBUNAL DE JUSTIÇA DO ESTADO DO RIO DE JANEIRO TJRJ DECISÃO

Cuida-se de Procedimento de Controle Administrativo proposto pelo Sindicato dos Servidores do Poder Judiciário do Estado do Rio de Janeiro Sindjustiça-RJ em face do Tribunal de Justiça daquele Estado, no qual pleiteia que o Conselho Nacional de Justiça promova mediação entre a categoria e a Administração da Justiça do Estado do Rio de Janeiro.

Determinada a intimação da parte requerida, o Tribunal de Justiça se manifestou no sentido de não querer participar de qualquer mediação a ser promovida pelo Conselho Nacional de Justiça.

Posteriormente, em 20 de dezembro de 2016, o sindicato requerente peticionou nos autos informando que a Corregedoria de Justiça havia editado, na mesma data, um provimento, de número 123/2016, determinando aos servidores grevistas que compensassem os dias de greve durante o recesso do Poder Judiciário. 
Ato seguinte, em 21 de dezembro de 2016, o sindicato peticionou novamente, aditando a petição anterior, e informando que além do Provimento 123/2016, a Corregedoria local havia editado outro provimento, de número 125/2016, o qual proibia os servidores grevistas de participar de escalas de revezamento elaboradas pelas serventias para o período de recesso.

Em 26 de dezembro, deferi liminar suspendendo os efeitos do provimento 123/2016, uma vez que a decisão analisou apenas os argumentos apresentados no dia 20 de dezembro de 2016.

Apenas após nova petição, protocolada em 27 de dezembro de 2016, foi observada a existência do pedido relativo à edição do Provimento 125/2016.

Por seu turno, a Corregedoria de Justiça, após tomar ciência quanto à Decisão Liminar proferida, apresentou manifestação na qual informou:

[...] o pedido de suspensão dos efeitos dos Provimentos CGJ no 123 e 125/2016 não guarda relação com os termos do pedido inicial. Trata-se, em verdade, de questão nova que deveria ter sido deduzida em procedimento de controle administrativo autônomo, sujeito à livre distribuição, razão por que o acolhimento parcial do pedido de liminar acabou por ofender o princípio da congruência e do juiz natural - aplicável nesse Conselho, ainda que se cuide aqui de demanda administrativa.

[...]

Registre-se, também, em sede preliminar, que o Sindjustiça impetrou o mandado de segurança no 0066552-83.2016.8.19.0000, em trâmite perante o Tribunal de Justiça do Estado do Rio de Janeiro, visando justamente sustar os efeitos dos Provimentos CGJ no 123 e 125/2016. Portanto, estando a questão judicializada, descabe qualquer intervenção do Conselho Nacional de Justiça.

\section{[...]}

No mérito, adiante se verá que a greve deflagrada pelo sindicato requerente é absolutamente abusiva, como, por sua vez, legais os Provimentos baixados, dentro do exercício de competência própria da CorregedoriaGeral da Justiça. Antes, porém, de demonstrar a legitimidade dos atos, vale deixar bem claro o que verdadeiramente move o Sindjustiça.

Não se sustenta sua afirmação de que a suspensão da greve, anunciada no final do 16/12/2016, uma sexta-feira, foi propiciada pela atitude desse Conselho Nacional de Justiça de buscar um acordo em janeiro 
próximo. Muito menos buscou a abertura de um canal de diálogo com o Tribunal de Justiça em pleno recesso! Se isso fosse verdade, não anunciaria previamente, como o fez em seu sítio na internet, o retorno à greve em 09/01/2017, ou seja, no primeiro dia útil imediatamente após o fim do recesso forense!

[...]

Ora, durante o recesso forense os cartórios trabalham apenas com expediente interno e, comumente, em regime de revezamento. Importa dizer que o servidor trabalha dois ou três dias nesse período, porém vê lançada sua frequência integralmente em todos os dias, assegurando o pagamento de seu salário mesmo em dias de ausência. E aí pensou o sindicato: a adesão dos grevistas a esse revezamento é algo bastante bom! Afinal, se estamos tendo o ponto cortado, seria uma ótima oportunidade de recebermos por dias não trabalhados, fortalecer o movimento e ainda aproveitar para descansar um pouco mais!

Mas como fazer parte de uma escala de revezamento se há uma greve em andamento? Afinal, greve pressupõe a paralisação dos serviços que, como também destacado pelo sindicato, chegou a 100\% de adesão em alguns cartórios. Reconhecendo, então, que a paralisação impediria a participação dos grevistas na escala de revezamento, posto que de si se espera a ausência ao serviço, o sindicato resolveu anunciar ao final do dia 16 de dezembro, uma sexta-feira, a suspensão da greve retroativa ao início do dia 16 de dezembro - já anunciando, repita-se, sua retomada após o fim do recesso. Explica-se, daí por que o Provimento CGJ nº 123/2016 só pôde ser elaborado no dia 19 de dezembro, segundafeira, e publicado no dia 20 de dezembro (terça-feira), na medida em que até então não se cogitava essa possibilidade.

O Provimento CGJ no 123/2016, entretanto, frustrou os planos do sindicato de assegurar aos grevistas frequência integral durante o recesso fugindo ao corte de ponto - em troca de alguns poucos dias de trabalho e de vários dias a mais de descanso. Daí, então, já no dia seguinte após sua edição resolveram retomar a greve.

$[\ldots]$

Eis, então, a razão da edição do Provimento CGJ no 125/2016 que já não mais trata de compensação de horas não trabalhadas, cogitável apenas quando retomadas as atividades. No caso, estabeleceu regras de controle de ponto do grevista durante o recesso, impossibilitado que 
está de se inserir em escala de revezamento diante de uma imprevisível presença e previsível ausência.

Ao não revelar esses motivos que o moveram, por certo o Sindjustiça induziu esse E. Conselho a erro que acabou por lhe deferir liminar com enorme perigo de dano inverso!

$[\ldots]$

Na verdade, aqui há o perigo de dano inverso. Ou seja, de se permitir que o grevista participe de uma escala de revezamento e, na condição de grevista, não compareça ao trabalho no dia escalado, deixando a serventia a descoberto para atender as necessidades do expediente interno, a exigir a presença de ao menos 2 servidores por dia em cada serventia, inclusive para atendimento de medidas de urgência. E mais, permitindo que recursos públicos venham a ser utilizados para seu pagamento sem a devida contraprestação do trabalho em um Estado em situação pré-falimentar.

Por isso, confia-se que a liminar deferida será reconsiderada na parte em que sustou os efeitos do Provimento CGJ no 123/2016 e, ainda, será negado o pleito de sustação dos efeitos dos Provimentos CGJ no $125 / 2016$.

$[\ldots]$

Por oportuno, pede-se nesta oportunidade a intervenção do Conselho Nacional de Justiça para a seguinte situação: o sindicato deflagrou uma greve absolutamente abusiva e, no entanto, como reconhece na sua petição sob o id. 2086197, não assegura o funcionamento mínimo do serviço essencial da justiça, permitindo que em algumas serventias a ausência seja de $100 \%$ do corpo de pessoal.

O resultado dessa prática desastrosa pode ser visto na enorme perda de produtividade, já a alcançar 35\% em novembro de 2016, no comparativo com novembro de 2015, conforme os gráficos trazidos e já antes referidos!

Porém, conforme a jurisprudência a seguir, deve o sindicato garantir uma presença de pelo menos $80 \%$ do pessoal para assegurar o funcionamento mínimo do serviço essencial da Justiça. Senão vejamos:

$[\ldots]$

Como o Sindjustiça não tem agido dessa forma, compactuando que serventias fiquem, simplesmente, sem qualquer servidor, como confessa na petição mencionada, é que neste momento se busca e se requer a 
tutela administrativa desse Conselho Nacional de Justiça para que, liminarmente, determine ao Sindjustiça que assegure a presença de $80 \%$ da força de trabalho em cartório, sob pena de suportar multa diária de $\mathrm{R} \$ 100.000,00$ (cem mil reais).

Por fim, em 11 de janeiro de 2016, o Sindicato requerente peticionou novamente, requerendo a análise quanto ao pedido para controle do provimento 125/2016, bem como para se determinar à CorregedoriaGeral de Justiça do Tribunal de Justiça do Estado do Rio de Janeiro que retire o lançamento de faltas injustificadas aos servidores durante o período do recesso, tendo em vista a incompatibilidade desta conduta com a decisão liminar proferida.

É o relatório. Decido.

Conforme se depreende do relato apresentado, cuida-se de Procedimento de Controle Administrativo proposto pelo Sindicato dos Servidores do Poder Judiciário do Estado do Rio de Janeiro com o pedido para que o Conselho Nacional de Justiça promova mediação entre o requerente e o requerido objetivando um acordo entre as partes.

A inicial protocolada foi expressa ao afirmar que: "É importante esclarecer, desde logo, que aqui não se busca, por ora, qualquer provimento material do Conselho Nacional de Justiça, mas tão somente a viabilização procedimental de um canal de diálogo que foi indevidamente negado pelo demandado".

Destarte, e com o intuito de promover a mediação requerida, determinei a intimação do Tribunal de Justiça do Estado do Rio de Janeiro que, em 1o de dezembro de 2016, se manifestou no sentido de não ter interesse em participar de qualquer mediação naquele momento (Id. 2070838).

Pois bem, neste sentido, há que se entender pela impossibilidade de procedência do pedido principal deste procedimento dado o desinteresse da parte requerida em, voluntariamente, participar de qualquer instrumento de mediação.

Posteriormente, quanto aos pedidos incidentais promovidos pelo requerente, entendo que a liminar proferida que analisou o Provimento 123/2016 se deu em caráter cautelar, em momento de extremo conflito entre as partes, e objetivou um apaziguamento necessário naquela quadra.

Passado o recesso forense, e de posse das contrarrazões apresentadas pela Corregedoria, forçoso se faz reconhecer que a parte requerente escolheu 
judicializar a questão relativa ao controle dos atos aqui questionados, o que determina, nesta instância, o encerramento da questão.

Diante desse cenário, conquanto inarredável a competência do Conselho Nacional de Justiça para o controle da atuação administrativa e financeira do Poder Judiciário, nos termos do parágrafo $4^{\circ}$ do artigo 103-B da Constituição Federal, é certo que, por razão de segurança jurídica e respeito à instância jurisdicional então provocada, não cabe avançar no debate de sorte a atingir, ainda que eventualmente, decisão judicial, ou nela interferir, evitando-se, assim, possíveis pronunciamentos conflitantes.

O posicionamento aqui adotado é pacífico no âmbito desta Casa, conforme se extrai de ementas de julgados do Plenário que ora transcrevo:

RECURSO ADMINISTRATIVOEM PROCEDIMENTODE CONTROLE ADMINISTRATIVO. OFICIAL SUBSTITUTA DE REGISTRO DE IMÓVEIS. INSURGÊNCIA CONTRA ATO DE COMISSÃO DE CONCURSO QUE DESIGNOU NOVA AUDIÊNCIA DE ESCOLHA DE SERVENTIAS EXTRAJUDICIAIS. REQUERENTE QUE NÃO FOI CANDIDATA NO REFERIDO CONCURSO. PRETENSÃO DE QUE SEJA DECLARADA A PERDA DE VALIDADE DO CONCURSO PARA QUE PERMANEÇA COMO SUBSTITUTA. QUESTÃO JUDICIALIZADA E SUBMETIDA AO STF ATRAVÉS DA ADI 3.522-3. IMPOSSIBILIDADE DE APRECIAÇÃO DA QUESTÃO. - "Se o concurso de ingresso no Serviço Público ou na atividade notarial e de registro for submetido à apreciação e crivo do Poder Judiciário, notadamente quando se alega inconstitucionalidade de preceitos legais que regem o certame, em ação própria, com efeito concentrado, tem-se que este certame, como um todo, ademais de ficar suspenso, fica submetido àquela decisão que virá a ser proferida no âmbito judicial pela Suprema Corte. Significa, portanto, que o Conselho Nacional de Justiça não tem competência para desconstituir atos praticados pelos Tribunais do País, em cumprimento a decisão do Supremo Tribunal Federal, sob pena de afronta à sua autoridade". (CNJ - RA - Recurso Administrativo em PCA - Procedimento de Controle Administrativo — 0002636-85.2008.2.00.0000 — Rel. RUI STOCO - 77a Sessão - j. 27/01/2009).

PROCEDIMENTO DE CONTROLE ADMINISTRATIVO. PRECATÓRIO. INDEFERIMENTO DO SEQUESTRO DE VERBAS PÚBLICAS PELO TRIBUNAL. MATÉRIA JUDICIALIZADA. NÃO CONHECIMENTO. 
I - Pedido de reforma da decisão administrativa que indeferiu o sequestro de verbas públicas para liquidação de precatório.

II - A decisão que originou o precatório ainda não se encontra transitada em julgado, estando em discussão judicial, inclusive contando com determinação recente do Superior Tribunal de Justiça no sentido de suspender a exigibilidade do valor relativo ao crédito constante do título.

III - A apreciação da matéria em foco na esfera jurisdicional gera óbice para o conhecimento dos argumentos expostos pelo requerente, tendo em vista que ao Conselho Nacional de Justiça foi atribuída competência apenas para o controle de legalidade dos atos administrativos emanados pelo Poder Judiciário, sem interferência sobre questões judiciais.

IV - Não conhecimento. (PCA 0005678-40.2011.2.00.0000, Rel. Cons. José Lucio Munhoz, 18.6.2012).

PROCEDIMENTOS DE CONTROLE ADMINISTRATIVO. PEDIDOS EQUIVALENTES FORMULADOS NA ESFERA ADMINISTRATIVA E JURISDICIONAL. MATÉRIA JUDICIALIZADA. NÃO CONHECIMENTO.

I - Pedidos equivalentes formulados nos processos levados a efeito pela requerente, quais sejam para suspender/sustar os efeitos dos itens " $\mathrm{b}$ " $\mathrm{e}$ "c" do Acórdão Administrativo no 10.690 do Conselho da Magistratura do Tribunal Estadual. Portanto, não restam dúvidas de que a matéria em foco já foi objeto de prévia apreciação na esfera jurisdicional, o que gera óbice para o conhecimento dos argumentos expostos pela requerente, tendo em vista que ao Conselho Nacional de Justiça foi atribuída competência apenas para o controle de legalidade dos atos administrativos emanados pelo Poder Judiciário, sem interferência sobre matéria judicial.

II - Não conhecimento. (PCA 0003199-74.2011.2.00.0000, Rel. Cons. José Lucio Munhoz, DJ 23.2.2012)

SERVENTIAS EXTRAJUDICIAIS. TAXA DE FISCALIZAÇÃO JUDICIÁRIA. MATÉRIA JUDICIALIZADA.

1. Não compete ao Conselho Nacional de Justiça apreciar Pedido de Providências cujo objeto coincida com o de ação judicial anteriormente proposta. 
2. Se previamente judicializada a matéria, o CNJ não pode examinar a questão na esfera administrativa, a bem de prestigiar-se a segurança jurídica, evitar-se interferência na atividade jurisdicional do Estado e afastar-se o risco de decisões conflitantes.

3. Recurso Administrativo em Pedido de Providência de que se conhece para, no mérito, negar-lhe provimento. (PP 2008.10.00.002567-1, Rel. Cons. João Oreste Dalazen, DJ 6.4.2009).

RECURSO ADMINISTRATIVO. PEDIDODE PROVIDÊNCIAS. HORÁRIO DE ATENDIMENTO AO PÚBLICO. QUESTÃO JUDICIALIZADA.

1. O inconformismo do recorrente cinge-se à questão do expediente no Juizado Especial/TJSP.

2. O horário de funcionamento das unidades judiciárias está no âmbito da autonomia do Tribunal de Justiça do Estado de São Paulo.

3. Suspensão da Resolução no 88 deste Conselho, que fixou o horário de expediente aos órgãos jurisdicionais, por decisão liminar deferida nos autos ADI nº 4.598, do Supremo Tribunal Federal, razão pela qual este Conselho não pode determinar ao TJSP que estenda o horário de funcionamento dos Juizados Especiais.

4. Ausência de ilegalidade ou qualquer medida a ser tomada pelo CNJ. Questão judicializada. Arquivamento do feito.

5. Recurso administrativo ao qual se nega provimento.

(CNJ - RA - Recurso Administrativo em PP - Pedido de Providências -

Conselheiro-0004160-44.2013.2.00.0000 - Rel.GUILHERMECALMON NOGUEIRA DA GAMA - 183a Sessão - j. 25/02/2014 ).

Por essas razões, e com fundamento no artigo 25, inciso VII, do Regimento Interno deste Conselho, julgo pela improcedência do pedido feito e considerando-se a liminar proferida sobre matéria judicializada, revogo os seus efeitos, determinando, por fim, o arquivamento dos autos.

Intimem-se.

Brasília 12 de janeiro de 2017.

Arnaldo Hossepian Junior

Conselheiro 